NOTA CIENTÍFICA

\title{
Cambios en las comunidades bacterianas de suelo luego de una contaminación con hexadecano
}

\section{Changes in soil bacterial communities after contamination with hexadecane}

\author{
Graciela N. Pucci, Adrián J. Acuña, Natalia Y. Nohra y Oscar H. Pucci
}

Universidad Nacional de la Patagonia San Juan Bosco. Centro de Estudios e Investigación en Microbiologla Aplicada (CEIMA) 4, Comodoro Rivadavia (CP 9000). Chubut, Argentina.

Email Graciela Pucci:

granapu@unpata.edu.ar

granapu@unpata.ed

Email Adrián Acuña:

ajcuna@unpata.edu.ar

Email Natalia Nohra: yamilano-

hra@hotmail.com

Email Oscar Pucci:

ceima@unpata.edu.ar

Presentado: $\quad$ 02/11/2011

Aceptado: $\quad$ 12/05/2012

$\begin{array}{ll}\text { Aceptado: } & 12 / 05 / 2012 \\ \text { Publicado online: } 01 / 10 / 2012\end{array}$

\section{Resumen}

El presente trabajo informa sobre los cambios en la comunidad bacteriana de un suelo proveniente de una zona hidrocarburífera de Argentina. Los cambios se observaron en un ensayo de microcosmo el cual fue sometido a contaminación con hexadecano. La determinacion de hidrocarburos y los recuentos bacterianos fueron realizados semanalmente. Los cambios en la diversidad bacteriana se determinaron por la el análisis de los ácidos grasos de membrana (FAMEs); identificándose y cuantificándose por cromatografía gaseosa utilizando los parámetros según MIDI. Se observó que la contaminación con hexadecano causa un disturbio en el suelo que conduce a un cambio en la estructura de la comunidad bacteriana.

Palabras claves: comunidades bacterianas, MIDI, suelo contaminado.

\section{Abstract}

This paper reports on changes in the soil bacterial community from a petroleum zone of Argentina. Changes were observed in a microcosm test which was subject to contamination with hexadecane. The determination of hydrocarbons and bacterial counts were performed weekly. Changes in bacterial diversity were determined by the analysis of membrane fatty acids (FAMEs), identified and quantified by gas chromatography using according to MIDI parameters. It was observed that contamination with hexadecane cause a disturbance in the soil leading to a change in the bacterial community structure.
La relación entre la contaminación ambiental y los cambios que ella produce sobre la comunidad bacteriana de un suelo es un tema bastante estudiado. La contaminación suele ocasionar la aparición de nuevas poblaciones bacterianas dominantes dentro de la comunidad establecida. Estas pueden sobrevivir a la contaminación, mejorando su capacidad fisiológica para la utilización del contaminante involucrado (Kumar y Khanna 2010). El objetivo de este trabajo fue evaluar el comportamiento de la comunidad bacteriana del sedimento de un arroyo seco, a las sucesivas contaminaciones con hexadecano.

El suelo investigado proviene de un arroyo seco de las inmediaciones de la ciudad de Comodoro Rivadavia en la Provincia de Chubut, Argentina. El cauce del arroyo atravesaba la cuenca hidrocarburífera del Golfo San Jorge. Para el desarrollo del trabajo, se diseñaron tres microcosmos, por triplicado, con un kilogramo de suelo cada uno. El microcosmo denominado LM1 sólo se le adicionó la muestra de suelo, al denominado LM2, además del suelo, se le incorporó nutrientes para lograr un relación C:N:P de 100:5:0,5 y agua destilada estéril para establecer la humedad del suelo en $20 \%$. El denominado LM3 se preparó en las mismas condiciones que LM2, y se contaminó inicialmente con $10000 \mathrm{mg} . \mathrm{kg}^{-1}$ de hexadecano. Luego de transcurridos 70 y 98 días se incorporó una nueva contaminación con 2000 mg. $\mathrm{kg}^{-1}$ de hexadecano en LM3 y se acondicionó nuevamente en LM2 y LM3 el contenido de nutrientes y humedad. Todos los microcosmos se incubaron por 105 días a 28 ${ }^{\circ} \mathrm{C}$ en oscuridad. El seguimiento de los microcosmos se realizó semanalmente por recuentos bacterianos por diseminación en superficie en medio TSBA (Britania) y por la determinación de hidrocarburos totales por espectrofotometría en el infrarrojo según la norma 418.1 de la Environmental Protection Agency. Las modificaciones en la diversidad de la comunidad bacteriana se determinó por ácidos grasos de membrana (FAMEs) totales extraídos del suelo según lo propuesto por Ritchie et al. (2000). Los ácidos grasos extraídos se identificaron y cuantificaron por cromatografía gaseosa utilizando los parámetros de corrida según MIDI-Sherlock (versión 6.0) (Sasser 1990). Los perfiles obtenidos fueron analizados mediante un análisis estadístico multivariado de componentes principales y se calculó el índice de diversidad de Shannon-Wiener. Ambos análisis se realizaron con el programa PAST.

El hexadecano es un hidrocarburo de cadena lineal que fácilmente puede ser degradado por los microorganismos del suelo ya que, prácticamente, no presenta toxicidad. Una comunidad bacteriana adaptada a la presencia de hidrocarburos, generalmente posee miembros que pueden responder rápidamente a la incorporación de este contaminante y comenzar a utilizarlo como fuente de carbono y energía (van Elsas et al. 2007), aumentando su número en los recuentos bacterianos, pero disminuyendo su biodiversidad (Atlas y Philp 2005). La utilización como fuente de carbono y energía en LM3 fue buena y rápida (Tabla 1), modificando la comunidad bacteriana y acercándose al estado original cuando el hidrocarburo disminuyó aproximadamente un 90\% (Fig. 1C). Los sucesivos agregados de hexadecano en los días 70 y 98 produjeron un resultado similar. Estas observaciones concuerdan con lo reportado por Fuller y Manning (2004) para bacterias gram positivas inhibidas por la presencia de TNT que, luego de ser removido el contaminante, su número se restableció. Stephen et al. (1999) sugirieron que la restauración de la estructura de la comunidad bacteriana a un estado similar a la que presentaban antes del disturbio producido por un contaminante, podría ser usada como parámetro para determinar el punto final, en términos ecológicos, de un proceso de biorremediación.

El suelo que solo fue movido de su lugar de origen y llevado al laboratorio, microcosmo LM1, también sufrió modificaciones, a pesar de no haber sido contaminado con hexadecano. Se observó 
Tabla 1. Determinaciones realizadas sobre los microcosmos estudiados.

\begin{tabular}{|c|c|c|c|c|c|c|c|c|c|c|}
\hline \multirow{2}{*}{ Días } & \multicolumn{3}{|c|}{ LM1 } & \multicolumn{3}{|c|}{ LM2 } & \multicolumn{4}{|c|}{ LM3 } \\
\hline & $g+/ g-$ & SW & UFC/g & $g+/ g-$ & SW & UFC/g & $g+/ g-$ & SW & UFC/g & TPH* \\
\hline Inicial & 6,24 & 4,141 & $5,0.10^{3}$ & 7,79 & 4,223 & $5,0.10^{3}$ & 5,50 & 1,889 & $5,0.10^{3}$ & 10000 \\
\hline 7 & 6,37 & 3,966 & & 7,65 & 4,021 & & 6,11 & 2,561 & & \\
\hline 14 & 5,99 & 4,086 & & 9,13 & 3,895 & & 5,83 & 2,613 & & \\
\hline 21 & 9,03 & 3,884 & & 8,16 & 3,86 & & 1,55 & 2,94 & & 3363 \\
\hline 29 & 9,53 & 3,966 & & 9,95 & 3,941 & & 1,40 & 3,004 & & 2200 \\
\hline 35 & 6,24 & 3,746 & & 7,14 & 4,207 & & 1,03 & 3,085 & & 1710 \\
\hline 42 & 2,81 & 3,816 & & 3,64 & 3,684 & & 1,22 & 3,031 & & 1135 \\
\hline 49 & 4,43 & 3,937 & & 1,72 & 4,096 & & 1,42 & 2,958 & & 314 \\
\hline 56 & 2,37 & 3,612 & & 3,54 & 3,588 & & 1,63 & 3,144 & & 328 \\
\hline 63 & 4,21 & 3,518 & $4,010^{2}$ & 2,40 & 3,17 & $3,0.10^{4}$ & 1,87 & 2,307 & $1,5.10^{7}$ & 101 \\
\hline 70 & 3,35 & 3,807 & & 2,80 & 3,579 & & 0,49 & 3,072 & & 1921 \\
\hline 77 & 2,76 & 3,525 & & 2,36 & 3,49 & & 0,68 & 3,105 & & 391 \\
\hline 84 & 3,51 & 4,04 & $1,3.10^{4}$ & 2,93 & 3,96 & $5,4.10^{4}$ & 1,02 & 3,197 & $1,4.10^{7}$ & 167 \\
\hline 98 & 2,59 & 3,753 & & 1,68 & 3,887 & & 0,64 & 2,846 & & 1827 \\
\hline 105 & 2,26 & 3,141 & $4,8 \cdot 10^{4}$ & 2,16 & 3,67 & $8,0.10^{5}$ & 0,75 & 3,455 & $1,2.10^{6}$ & 354 \\
\hline
\end{tabular}

g+/g-: Índice de bacterias gran positivas/gran negativas $((\Sigma$ 15:0i $+15: 0$ anteiso + 16:0i + 16:0 ai + 17:0 i + 17:0 ai $) /(\Sigma 17 \mathrm{cy}+18: 1 \omega 7 \mathrm{c}+19: 0$ cy $))$. SW: índice de biodiverisidad de Shannon-Wiener. TPH: hidrocarburos totales expresados en $\mathrm{mg} \cdot \mathrm{kg}^{-1}$.

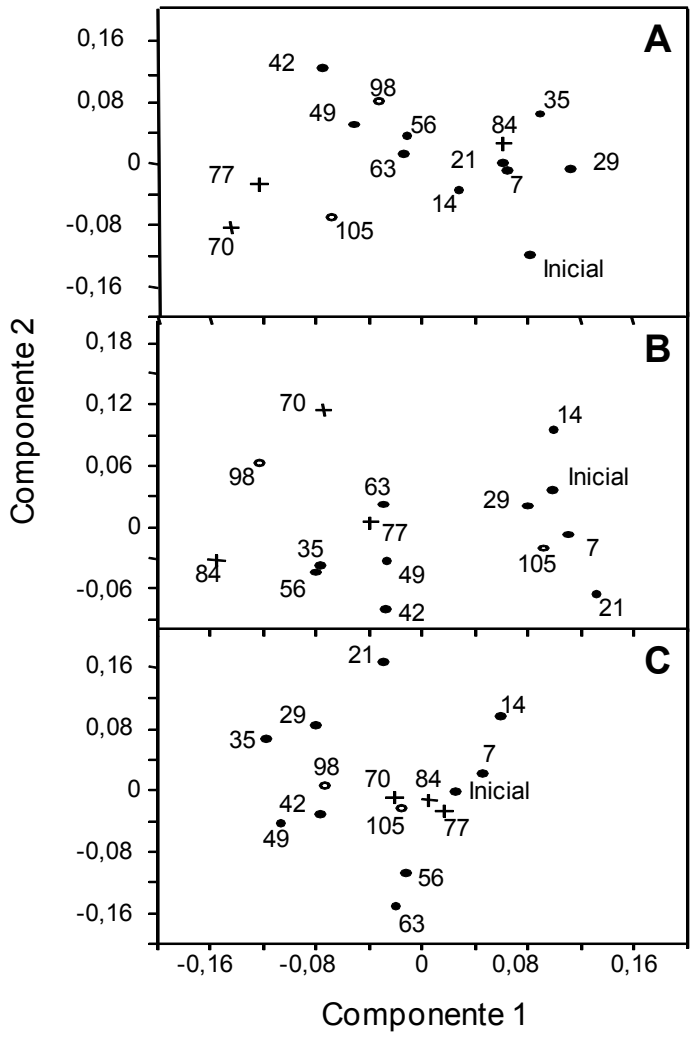

Figura 1. Análisis estadístico multivariado de componentes principales en los tres sistemas estudiados. El gráfico A, B y C corresponden a los microcosmos LM1, LM2 y LM3 respectivamente. Los círculos llenos, vacíos y las cruces representan los diferentes períodos del estudio para diferenciar las incorporaciones de hexadecano y/o nutrientes, dependiendo del sistema.

una modificación en el valor del índice de Shannon-Wiener, con un número de bacterias constante en el tiempo. La dispersión de la comunidad bacteriana también existió (Fig. 1A), acompañada de una modificación del índice de gram positivos/gram negativos que muestra un aumento de los microorganismos gram positivos en los días 21 y 35 para luego decaer y mantenerse en valores bajos. El tiempo produjo un agotamiento de los pocos nutrientes existentes en el suelo y la falta de agregado de humedad generó la dispersión de las muestras sin que puedan permanecer juntas o volver a valores próximos a los del inicio del ensayo.
El agregado de nutrientes provocó un disturbio formando tres grupos en el análisis estadístico (Fig. 1B), generados a partir de las tres veces que se incorporó nutrientes. Los recuentos bacterianos realizados en TSBA no presentaron modificaciones en el tiempo de estudio. En el día 42 se produjo una modificación en la cantidad de bacterias gram negativas que se mantuvo con el tiempo y los agregados de nutrientes.

De los resultados expuestos se puede estimar que la presencia de un contaminante como el hexadecano produce un disturbio en el suelo que conduce a un cambio en la estructura de la comunidad bacteriana del mismo. Es importante remarcar que el solo hecho de mover el suelo o incorporarle nutrientes, también implica modificaciones en la comunidad bacteriana, pero que se manifiestan de manera diferente a las producidas por el contaminante.

\section{Literatura citada}

Atlas R.M. \& J. Philp. 2005. Bioremediation: applied microbial solutions for real-world environmental cleanup. American Society for Microbiology (ASM) Press, Washington, DC, 78-105.

Kumar M. \& S. Khanna. 2010. Diversity of 16S rRNA and dioxygenase genes detected in coal tar-contaminated site undergoing active bioremediation. J. Appl. Microbiol. 108: 1252-1262.

Fuller M.E. \& J.F. Manning. 2004. Microbiological changes during bioremediation of explosives-contaminated soils in laboratory and pilot-scale bioslurry reactors. Bioresour. Technol. 91: 123-133.

Ritchie N.J., M.E. Schutter, R.P. Dick et al. 2000. Use of length heterogeneity PCR and fatty acid methyl ester profiles to characterize microbial communities in soil. Appl. Environ. Microbiol. 66: 1668-1675.

Sasser M. 1990. Identification of bacteria by gas chromatography of cellular fatty acids. Technical note 101. Microbial ID, Newark, Del.

van Elsas J.D., J.K. Jansson \& J.K. Trevors. 2007. Modern soil microbiology, 2nd edn. CRC Press, New York, pp 387-429.

Stephen J.R., Y.I. Chang, Y.D. Gan et al. 1999. Microbial characterization of a JP-4 fuel-contaminated site using a combined lipid biomarker/polymerase chain reaction-denaturing gradient gel electrophoresis (PCRDGGE)- based approach. Appl. Environ. Microbiol. 1: 231-241. 